\title{
Iron limitation promotes the atrophy of skeletal myocytes, whereas iron supplementation prevents this process in the hypoxic conditions
}

\author{
KAMIL KOBAK $^{1}$, MONIKA KASZTURA ${ }^{1}$, MAGDALENA DZIEGALA ${ }^{1}$, JACEK BANIA ${ }^{2}$, \\ VIOLETTA KAPUŚNIAK ${ }^{3}$, WALDEMAR BANASIAK ${ }^{4}$, PIOTR PONIKOWSKI ${ }^{4,5}$ and EWA A. JANKOWSKA ${ }^{1,4}$ \\ ${ }^{1}$ Laboratory for Applied Research on Cardiovascular System, Department of Heart Diseases, Wrocław Medical University, \\ 50-981 Wrocław; ${ }^{2}$ Department of Food Hygiene and Consumer Health; ${ }^{3}$ Department of Histology and Embryology, \\ Wroclaw University of Environmental and Life Sciences, 50-375 Wroclaw; ${ }^{4}$ Centre for Heart Diseases, Military Hospital, \\ 50-981 Wrocław; ${ }^{5}$ Department of Heart Diseases, Wrocław Medical University, 50-367 Wrocław, Poland
}

Received August 21, 2017; Accepted January 18, 2018

DOI: $10.3892 / \mathrm{ijmm} .2018 .3481$

\begin{abstract}
There is clinical evidence that patients with heart failure and concomitant iron deficiency have increased skeletal muscle fatigability and impaired exercise tolerance. It was expected that a skeletal muscle cell line subjected to different degrees of iron availability and/or concomitant hypoxia would demonstrate changes in cell morphology and in the expression of atrophy markers. L6G8C5 rat skeletal myocytes were cultured in normoxia or hypoxia at optimal, reduced or increased iron concentrations. Experiments were performed to evaluate the iron content in cells, cell morphology, and the expression of muscle specific atrophy markers [Atroginl and muscle-specific RING-finger $1(M u R F 1)]$, a gene associated with the atrophy/hypertrophy balance [mothers against decapentaplegic homolog 4 (SMAD4)] and a muscle class-III intermediate filament protein (Desmin) at the mRNA and protein level. Hypoxic treatment caused, as compared to normoxic conditions, an increase in the expression of Atrogin-1 $(\mathrm{P}<0.001)$. Iron-deficient cells exhibited morphological abnormalities and demonstrated a significant increase in the expression of Atrogin-1 $(\mathrm{P}<0.05)$ and MuRF1 $(\mathrm{P}<0.05)$ both in normoxia and hypoxia, which indicated activation of the ubiquitin proteasome pathway associated with protein degradation during muscle atrophy. Depleted iron in cell culture combined with hypoxia also induced a decrease in SMAD4 expression $(\mathrm{P}<0.001)$ suggesting modifications leading to atrophy. In contrast, cells cultured in a medium enriched with iron
\end{abstract}

Correspondence to: Professor Ewa A. Jankowska, Laboratory for Applied Research on Cardiovascular System, Department of Heart Diseases, Wrocław Medical University, Weigla 5, 50-981 Wrocław, Poland

E-mail: ewa.jankowska@umed.wroc.pl

Key words: muscle atrophy, iron deficiency, iron excess, hypoxia, skeletal myocytes during hypoxia exhibited inverse changes in the expression of atrophy markers (both $\mathrm{P}<0.05$ ). Desmin was upregulated in cells subjected to both iron depletion and iron excess in normoxia and hypoxia (all $\mathrm{P}<0.05)$, but the greatest augmentation of mRNA expression occurred when iron depletion was combined with hypoxia. Notably, in hypoxia, an increased expression of Atrogin-1 and MuRFl was associated with an increased expression of transferrin receptor 1 , reflecting intracellular iron demand $(\mathrm{R}=0.76, \mathrm{P}<0.01 ; \mathrm{R}=0.86, \mathrm{P}<0.01)$. Hypoxia and iron deficiency when combined exhibited the most detrimental impact on skeletal myocytes, especially in the context of muscle atrophy markers. Conversely, iron supplementation in in vitro conditions acted in a protective manner on these cells.

\section{Introduction}

Muscle atrophy reflects a systemic response to various chronic conditions, including heart failure (HF) $(1,2)$. Disease-associated decreases in the size of muscle tissue can occur as a result of various pathologies and one such reported causative factors is hypoxia (3-5).

Exercise intolerance and skeletal muscle dysfunction are among the fundamental features of HF pathophysiology, and are associated with limited everyday function and poor patient outcomes (6-8). The mass and volume of skeletal muscle in different regions of the body are decreased in patients with HF (9-12), and skeletal muscles are more prone to exertion fatigue $(13,14)$. The skeletal muscle wasting known as cardiac cachexia (15) may also be observed in histopathological evaluations where fibre atrophy is observed $(16,17)$ and at the molecular level as the proteolysis by the ubiquitin-proteasome system is activated (18).

Iron deficiency is one of the potential pathomechanisms that contribute to muscle dysfunction in HF (19-21). The beneficial effects of iron supplementation on the improvement of muscle function in patients with HF have already been reported $(22,23)$; however, the associated mechanisms remain to be elucidated. 
It may be hypothesized that the disturbed iron metabolism observed in HF affects skeletal muscles, which leads to their dysfunction and exercise intolerance. The present authors have recently demonstrated that, during hypoxia, reduced iron concentration had a greater negative impact on the viability and functioning of myocytes, compared with augmented iron availability (24).

As hypoxic conditions, which occur in the course of HF are difficult to be introduced and manipulated in humans and animals, a model of skeletal myocyte cultures was established in the present study. The aim of the present study was to investigate the influence of iron availability and hypoxia in the context of muscle atrophy markers and cell morphology in a rat skeletal myocyte cell line (L6G8C5).

The following parameters were measured in the L6 cell line using differing states of iron availability in the culture medium: Atrogin-1 and muscle-specific RING-finger 1 (MuRF-1), which are muscle-specific ubiquitin E3-ligases that are a part of the ubiquitin proteasome pathway associated with protein degradation during muscle atrophy, and are markedly induced in almost all types of atrophy (25-27); mothers against decapentaplegic homolog 4 (SMAD4), which is a transcriptional factor that serves a central role in the balance between atrophy and hypertrophy (28-30); and Desmin, which is a structural protein that builds class-III intermediate filaments found in muscle cells. B cell lymphoma-2 (Bcl-2) associated protein $\mathrm{X}(\mathrm{Bax}) / \mathrm{Bcl}-2$ gene expression ratio (31) and expression of transferrin receptor 1 (TfRI) (32) were evaluated as previously described (24), to evaluate apoptotic activity and iron influx, respectively.

\section{Materials and methods}

Experimental schedule. Rat L6G8C5 skeletal myocytes (L6; Sigma-Aldrich; Merck KGaA, Darmstadt, Germany) were cultured in normoxia $\left(18 \% \mathrm{O}_{2}, 5 \% \mathrm{CO}_{2}\right)$ or hypoxia $\left(1 \% \mathrm{O}_{2}\right.$, $5 \% \mathrm{CO}_{2}, 94 \% \mathrm{~N}_{2}$ ), for $48 \mathrm{~h}(24)$, supplemented with $100 \mu \mathrm{M}$ deferoxamine (DFO; Sigma-Aldrich; Merck KGaA) or $200 \mu \mathrm{M}$ ammonium ferric citrate (AFC; Sigma-Aldrich; Merck KGaA) in order to change iron accessibility (Fig. 1). Controls were grown in normal cell culture conditions in normoxia for $48 \mathrm{~h}$. DFO is a selective iron chelator that is typically used in cell culture studies. It has been reported that the addition of DFO into culture medium reduces iron concentration both in the cellular environment and inside the cell, as DFO may be taken up via fluid phase endocytosis (33). AFC was previously applied in cell culture studies in order to induce intracellular iron uptake $(34,35)$. Compounds were added to cells from 1,000X concentrated stock, diluted in culture medium. Hypoxia was generated in a standard cell culture incubator by displacing $\mathrm{O}_{2}$ with infusion of $\mathrm{N}_{2}$, which was supplied by an external high-pressure liquid nitrogen tank.

Cell culture conditions. L6 cells were grown in $37^{\circ} \mathrm{C}$ in Dulbecco's modified Eagle's medium(DMEM; Sigma-Aldrich; Merck KGaA) with the addition of $10 \%$ fetal bovine serum (FBS; Invitrogen; Thermo Fisher Scientific, Inc., Waltham, MA, USA), $2 \mathrm{mmol} / 1$ glutamine, $1 \mathrm{U} / \mathrm{ml}$ penicillin and $10 \mathrm{mg} / \mathrm{ml}$ streptomycin (all from Sigma-Aldrich; Merck $\mathrm{KGaA}$ ). For passages, cells were washed with PBS (without ions $\mathrm{Ca}^{2+}$ and $\mathrm{Mg}^{2+}$ ) and released via the use of Trypsin (Sigma-Aldrich; Merck KGaA). Cells were maintained according to manufacturer's guidelines.

Iron content in cells. The measurement of intracellular iron content was performed via flame atomic absorption spectroscopy assay (36). Briefly, $2 \times 10^{6}$ cells, cultured according to the aforementioned protocol, were dissociated by trypsinisation, pelleted by centrifugation ( $5 \mathrm{~min}$; room temperature; $500 \mathrm{x} \mathrm{g}$ ), and washed five times with PBS in order to remove free iron ions from the medium. The pellet was dissolved in $250 \mu \mathrm{l}$ radioimmunoprecipitation assay (RIPA) buffer (Sigma-Aldrich; Merck KGaA) for $30 \mathrm{~min}$ on ice and sonicated on ice $(20 \mathrm{kHz} ; 10 \mathrm{sec})$ to disaggregate cellular structures. The protein concentration in the cell lysate was determined using the Lowry method (37). Intracellular iron content was measured in $250 \mu \mathrm{l}$ of medium containing $1 \mathrm{mg}$ protein lysate using an atomic absorption spectrometer (SOLAAR M6; Thermo Elemental, Ltd., Cambridge, UK) equipped with a deuterium lamp for background radiation correction by direct calibration against aqueous standards. An air-acetylene flame was used (gas flow, $0.9 \mathrm{l} / \mathrm{min}$ ). The calibration solutions were prepared following successive dilutions of the stock standard solution (iron standard for AAS TraceCERT; 1,000 ppm; Sigma-Aldrich; Merck KGaA). The final iron concentration in the successive dilutions of the stock solution varied from 0.5-2.0 ppm. All solutions were diluted to 1:5 with deionized water. Measurements were made under the following conditions: Burner, $100 \mathrm{~mm}$; wavelength, $\lambda=253.7 \mathrm{~nm}$; background correction (quadline bandpass, $0.2 \mathrm{~nm}$ ); lamp current, $75 \%$. The method was verified by determination of reference material [Seronorm ${ }^{\mathrm{TM}}$ Trace Elements Serum level I: $\mathrm{Fe}=1.39 \mathrm{mg} / \mathrm{l}$; level II: $\mathrm{Fe}=1.91 \mathrm{mg} / \mathrm{l}$ (SERO AS, Billingstad, Norway)].

Reverse transcription-quantitative polymerase chain reaction $(R T-q P C R)$. Total RNA was isolated from L6 cells harvested from 6-well tissue culture plates (Sarstedt AG, Göttingen, Germany) using the RNeasy ${ }^{\circledR}$ Fibrous Tissue Mini kit (Qiagen $\mathrm{GmbH}$, Hilden, Germany) according to the manufacturer's instructions. The protocol included an on-column DNAse digestion to remove genomic DNA. First-strand cDNA was synthesized using a SuperScript ${ }^{\mathrm{TM}}$ III First-Strand Synthesis system with oligo(dT) $)_{20}$ primer according to the manufacturer's protocol (Invitrogen; Thermo Fisher Scientific, Inc.). The following primer sequences were used and designed with Molecular Beacon Software (Bio-Rad Laboratories, Inc., Hercules, CA, USA): Atrogin-1 forward, 5'-AGCTTGTGC GATGTTACCCA-3' and reverse, 5'-GAGCAGCTCTCTGGG TTGTT-3'; MuRF1 forward, 5'-TGCAAGGAACACGAAGAC GA-3' and reverse, 5'-ACAAGGAGCAAGTAGGCACC-3'; SMAD4 forward, 5'-CGGGTTGTCTCACCTGGAAT-3' and reverse, 5'-TGGATGCGCGATTACTTGGT-3'; Desmin forward, 5'-GACCTTCTCTGCTCTCAACTTCC-3' and reverse, 5'-CGCTGACGACCTCTCCATCC-3'; $\mathrm{Bcl}$-2 forward, 5'-AGCATGCGACCTCTGTTTGA-3' and reverse, 5'-TCA CTTGTGGCCCAGGTATG-3'; Bax forward, 5'-TGGCGA TGAACGGACAACA-3' and reverse, 5'-CACGGAAGAAGA CCTCTCGG-3'; and TfR1 forward, 5'-GAGACTACTTCC GTGCTACTTC-3' and reverse, 5'-TGGAGATACATAGGG 


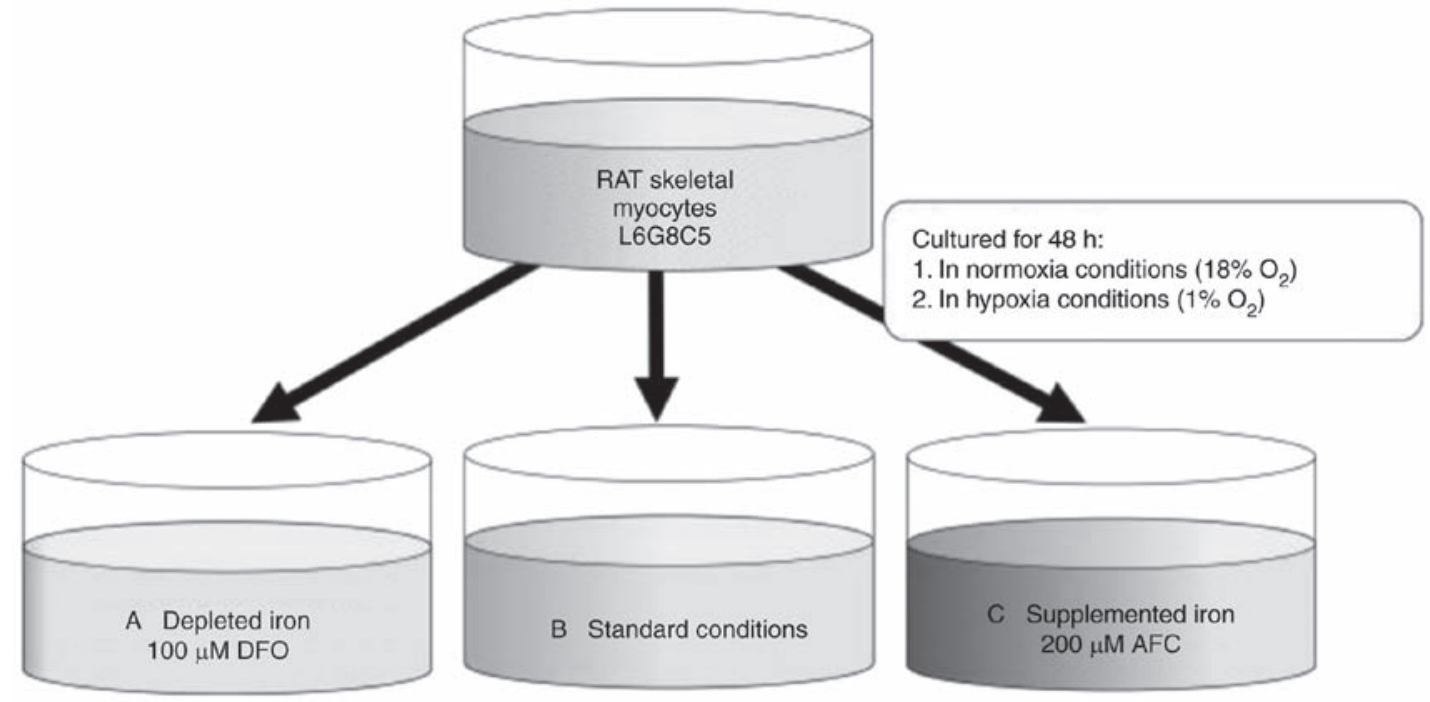

Figure 1. Different oxygen availability conditions (normoxia and hypoxia) with L6G8C5 myocytes cell culture and iron concentration manipulations. The following conditions are presented: (A) Reduced iron concentration (iron chelation using $100 \mu \mathrm{M} \mathrm{DFO}$ ); (B) optimal iron concentration (standard iron concentration in Dulbecco's modified Eagle's medium with 10\% fetal bovine serum); and (C) increased iron concentration (iron supplementation with $200 \mu \mathrm{M}$ AFC). DFO, deferroxamine; AFC, ammonium ferric citrate.

TGACAGG-3'. The primers spanned exon junctions to prevent the amplification of genomic DNA. The reference genes, $\beta$-actin (actb; Rattus norvegicus) and $18 S$ ribosomal RNA (rRNA; 18s; Rattus norvegicus), were provided with a geNorm kit (ge-SY-12; PrimerDesign, Ltd., Southampton, UK) and used in all measurements. All experiments were performed in triplicate. The qPCR assay (consisting of an initial denaturation step at $95^{\circ} \mathrm{C}$ followed by 40 cycles of denaturation steps at $95^{\circ} \mathrm{C}$ for $10 \mathrm{sec}$ and primer annealing/extension at $60^{\circ} \mathrm{C}$ for $15 \mathrm{sec}$ ) was performed using the CFX Connect ${ }^{\mathrm{TM}}$ Real-Time PCR Detection system and SsoFast ${ }^{\mathrm{TM}}$ EvaGreen $^{\circledR}$ Supermix reagent (both from Bio-Rad Laboratories, Inc.). The specificity of PCR was determined by melt-curve analysis for each reaction. The amplification efficiency was estimated by running serial dilutions of a template. Successive dilutions were plotted against the appropriate $\mathrm{Cq}$ values to generate a standard curve. The slope calculated from the standard curve was used to determine the amplification efficiency (E) according to the formula: $\mathrm{E}=10^{-1} /$ slope. The amplification efficiencies for the target amplicons, $\beta$-actin and $18 S$ rRNA were not comparable and the Pfaffl method was used to determine the relative expression (38).

Western blotting. L6 cells were homogenised on ice in RIPA buffer [10 mM Tris-Cl (pH 8.0), 1 mM EDTA, $0.5 \mathrm{mM}$ EGTA, $1 \%$ Triton X-100, $0.1 \%$ sodium deoxycholate, $0.1 \%$ SDS, $140 \mathrm{mM} \mathrm{NaCl}, 1 \mathrm{mM}$ PMSF] for $60 \mathrm{~min}$, followed by sonication on ice $(20 \mathrm{kHz} ; 10 \mathrm{sec})$. Protein concentration was estimated by BCA assay (39). In order to determine Atrogin-1, MuRF-1, SMAD4 and desmin protein levels, $30 \mu \mathrm{g}$ appropriate protein lysates $(\sim 10 \mu \mathrm{l})$ were separated by $12 \%$ SDS-PAGE. Proteins were electro-transferred on polyvinylidene fluoride membranes (EMD Millipore, Billerica, MA, USA) in Towbin buffer ( $25 \mathrm{mM}$ Tris, $192 \mathrm{mM}$ glycine) supplemented with $20 \%$ methanol. Membranes were blocked with 5\% skimmed milk for $1 \mathrm{~h}$ at room temperature and incubated with primary antibodies (Table I) overnight at $4^{\circ} \mathrm{C}$. Following washing (3x10 min; TBS, Tween-20), membranes were incubated with secondary horseradish peroxidase-conjugated anti-rabbit and anti-mouse antibodies (Table I) and developed with ECL or Femto detection systems (Pierce; Thermo Fisher Scientific, Inc.). The data was obtained from three separate experiments.

Immunofluorescence and imaging. For immunofluorescence, cells were grown to 70-90\% confluency on sterile coverslips placed in 6-well plates (Sarstedt AG). Cells were fixed in 4\% formalin in PBS for 20 min at room temperature, then unmasked in Target Retrieval Solution (pH 9; Dako; Agilent Technologies, Inc., Santa Clara, CA, USA) in $95^{\circ} \mathrm{C}$ for $10 \mathrm{~min}$, permeabilized with $0.1 \%$ Triton $\mathrm{X}-100$ in PBS $(3 \times 7 \mathrm{~min})$, washed with PBS and blocked at room temperature for $1 \mathrm{~h}$ with PBS containing 10\% FBS. Double-immunofluorescence staining was applied as cells were incubated overnight at $4^{\circ} \mathrm{C}$ with primary antibodies (Table I), washed with PBS and subsequently incubated for $2 \mathrm{~h}$ at room temperature with fluorescein isothiocyanatae- or rhodamine-conjugated secondary antibodies (Table I) and DAPI ( $2 \mu \mathrm{g} / \mathrm{ml}$; Santa Cruz Biotechnology, Inc., Dallas, TX, USA) as a nuclei marker. Control reactions were performed without primary antibodies. Labelled cells were mounted in ProLong Gold Antifade Mountant (Thermo Fisher Scientific, Inc.). Cells were viewed using a Nikon Eclipse 80 i fluorescence microscope (Nikon Corp., Tokyo, Japan) with 40x objective lens. Representative images were chosen from each sample and were processed with the use of ImageJ $1.51 \mathrm{~h}$ (National Institutes of Health, Bethesda, MD, USA). Data was obtained from three separate experiments.

Statistical analysis. Data are presented as the mean \pm standard deviation unless otherwise indicated. Kruskall-Wallis analysis followed by post-hoc Dunn's multiple comparison test was used to compare the groups. All experiments were performed in triplicate. Spearman's rank correlation coefficient was calculated between the expression of Atrogin-1, MuRF-1, SMAD4 and Desmin genes in three states of iron concentrations or 
Table I. Antibodies and dilutions used for WB and IF.

\begin{tabular}{llll}
\hline Antigen & Application (dilution) & \multicolumn{1}{c}{ Manufacturer } & Cat. no. \\
\hline $\begin{array}{l}\text { Atrogin-1 } \\
\text { MuRF1 }\end{array}$ & WB $(1: 200)$, IF $(1: 100)$ & Santa Cruz Biotechnology, Inc. & sc-166806 \\
SMAD4 & WB $(1: 200)$, IF $(1: 100)$ & Santa Cruz Biotechnology, Inc. & sc-7966 \\
Desmin & WB $(1: 200)$, IF $(1: 50)$ & Santa Cruz Biotechnology, Inc. & sc-14026 \\
Actin HRP & WB $(1: 200)$, IF $(1: 100)$ & Santa Cruz Biotechnology, Inc. & sc-1616 HRP \\
Rabbit IgG HRP & WB $(1: 5,000)$ & Santa Cruz Biotechnology, Inc. & A11-035-045 \\
Mouse IgG HRP & WB $(1: 15,000)$ & Jackson ImmunoResearch Laboratories, Inc. & A 9917 \\
Rabbit IgG R & WB $(1: 15,000)$ & Sigma-Aldrich; Merck KGaA & sc-2091 \\
Mouse IgG FITC & IF $(1: 500)$ & Santa Cruz Biotechnology, Inc. & sc-2010 \\
\hline
\end{tabular}

Company locations are as follows: Santa Cruz Biotechnology, Inc. (Dallas, TX, USA); Jackson ImmunoResearch Laboratories, Inc. (West Grove, PA, USA); Sigma-Aldrich (Merck KGaA; Darmstadt, Germany). WB, western blotting; IF, immunofluorescence; MuRF1, muscle-specific RING-finger 1; SMAD4, mothers against decapentaplegic homolog 4; IgG, immunoglobulin G; HRP, horseradish peroxidase; R, rhodamine; FITC, fluorescein isothiocyanate.

between expression of the aforementioned genes and $\mathrm{Bax} / \mathrm{Bcl} 2$ or $T f R 1$ in those same conditions. $\mathrm{P}<0.05$ was considered to indicate a statistically significant difference.

\section{Results}

Changes in intracellular iron due to the addition of DFO or AFC to culture media. The mean intracellular content of iron in L6 cells in the standard DMEM medium was $0.91 \mathrm{mg} / \mathrm{l}$. The direct measurement of intracellular iron demonstrated that the addition of $100 \mu \mathrm{M}$ DFO to the medium caused a decrease of intracellular iron concentration to $0.41 \mathrm{mg} / \mathrm{l}$. In contrast, a supplementation of medium with $200 \mu \mathrm{M}$ AFC increased mean intracellular iron concentration to $5.12 \mathrm{mg} / \mathrm{l}$ (data not shown).

Effects of differing iron availability during normoxia or hypoxia on the morphology of skeletal myocytes. The exposition of skeletal myocytes to hypoxia alone did not markedly affect the morphology of the studied cell line. Notably, the morphological abnormalities within skeletal myocytes, such as cell shrinkage and pyknosis, occurred upon decreased iron availability in both normoxic and hypoxic conditions. In turn, AFC treatment upon both optimal and reduced oxygen concentration did not lead to any marked alterations in cellular morphology (Fig. 2).

Effects of differing iron availability on the atrophy markers Atrogin-1 and MuRF1 in skeletal myocytes. The effect of iron availability on levels of Atrogin-1 and MuRF1 were assessed (Fig. 3). Hypoxic treatment of L6 skeletal myocytes caused, as compared with the untreated cells, a significant increase in mRNA expression of Atrogin-1 $(\mathrm{P}<0.001$; Fig. 3A). L6 cells when exposed to iron-deficient environment demonstrated, as compared with the cells cultured in optimal iron concentration, significantly increased mRNA expression of Atrogin-1 in both normoxia $(\mathrm{P}<0.01)$ and hypoxia $(\mathrm{P}<0.05$; Fig. 3A), indicating enhanced protein degradation in the cells. Notably, the increase in Atrogin-1 mRNA expression was greater during hypoxia and concomitant reduced iron availability than in hypoxia alone $(\mathrm{P}<0.05)$. In turn, AFC treatment of myocytes did not significantly affect the mRNA expression of Atrogin-1 under optimal oxygen levels, whereas during hypoxia the expression of the aforementioned marker was significantly decreased, as compared with cells cultured in optimal $(\mathrm{P}<0.05)$ and reduced iron concentrations $(\mathrm{P}<0.001$; Fig. 3A). Western blot analysis and immunocytochemical staining revealed similar patterns of changes at the protein level (Fig. 3C and D).

Low oxygen concentration did not significantly affect the mRNA expression of MuRF1 (Fig. 3B), as compared with untreated cells. The exposure to DFO induced a significant increase in mRNA expression of $M u R F 1$ in normoxia $(\mathrm{P}<0.05)$ and hypoxia $(\mathrm{P}<0.05)$, as compared with cells cultured in optimal iron concentration. Notably, skeletal myocytes demonstrated a greater increase in mRNA expression of $M u R F 1$ when cultured in low iron availability during hypoxia than in normoxic conditions. In turn, increased iron availability induced a significant decrease in mRNA expression of $M u R F 1$ during normoxia $(\mathrm{P}<0.05)$ and hypoxia $(\mathrm{P}<0.001)$, compared with optimal iron levels. Western blot analysis and immunocytochemical staining revealed similar patterns of changes at the protein level (Fig. 3C and E). Notably, the mRNA expression of MuRF1 during hypoxia was significantly associated with mRNA expression of Atrogin-1 $(\mathrm{R}=0.98, \mathrm{P}<0.001)$ regardless of iron status. Further, in hypoxia an increased expression of Atrogin-1 and MuRF1 was associated with an increased expression of $T f r l$ (24), reflecting intracellular iron demand ( $\mathrm{R}=0.91, \mathrm{P}<0.01 ; \mathrm{R}=0.86, \mathrm{P}<0.01$; data not shown). The aforementioned associations were not observed under normoxic conditions.

Effects of differing iron availability on the expression of SMAD4 in skeletal myocytes. The exposure of skeletal myocytes to hypoxia alone did not significantly affect the mRNA expression of SMAD4. In turn, reduction of iron availability resulted, as compared with the cells cultured in optimal iron concentrations, in significantly decreased mRNA expression of SMAD4 under hypoxia $(\mathrm{P}<0.001)$, suggesting 

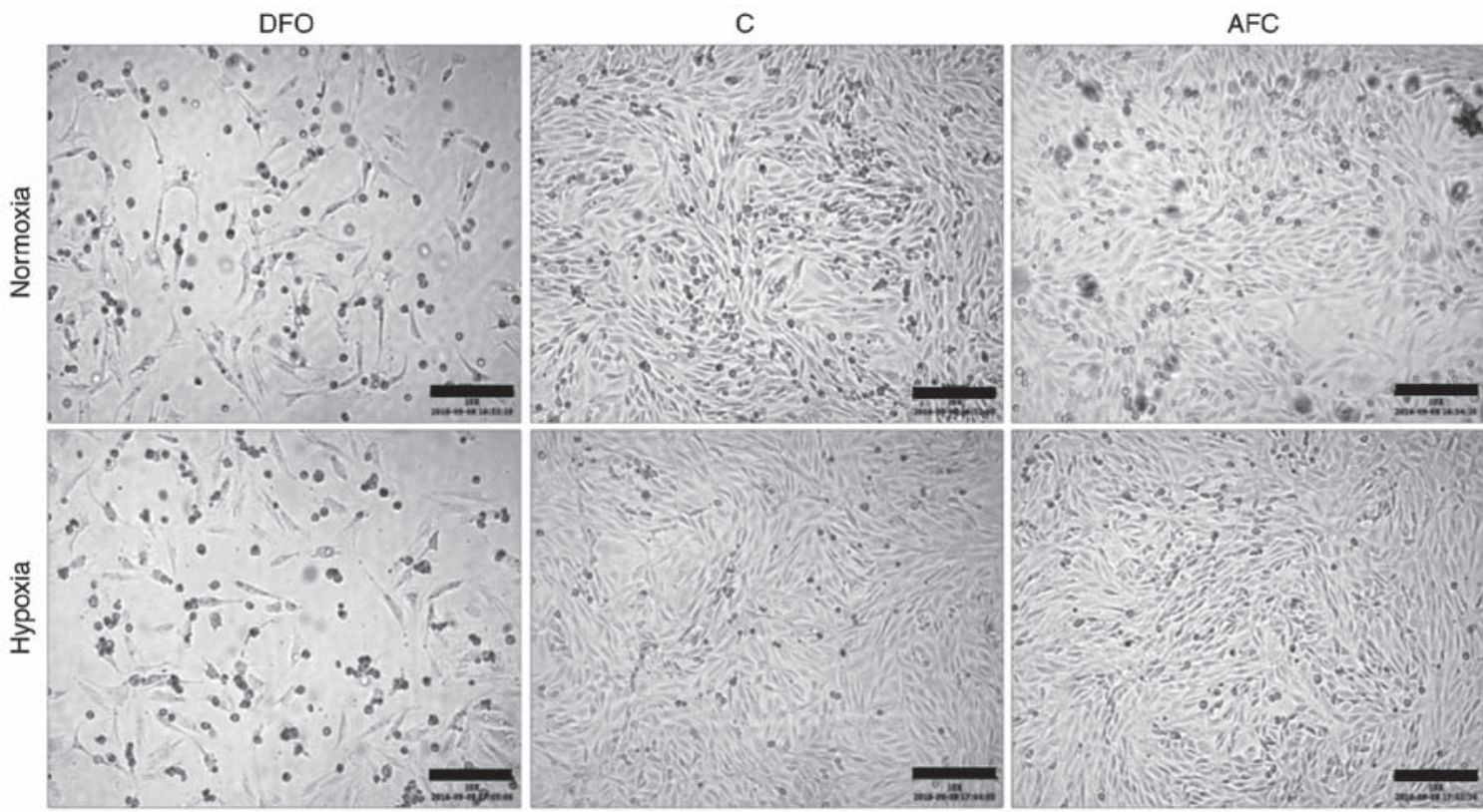

Figure 2. Bright field inverted microscope images of L6G8C5 cells in different iron availability conditions in normoxia and hypoxia. Scalebar length, $200 \mu \mathrm{m}$ $\mathrm{DFO}$, reduced iron concentration via deferroxamine; $\mathrm{C}$, control; $\mathrm{AFC}$, increased iron concentration via ammonium ferric citrate.
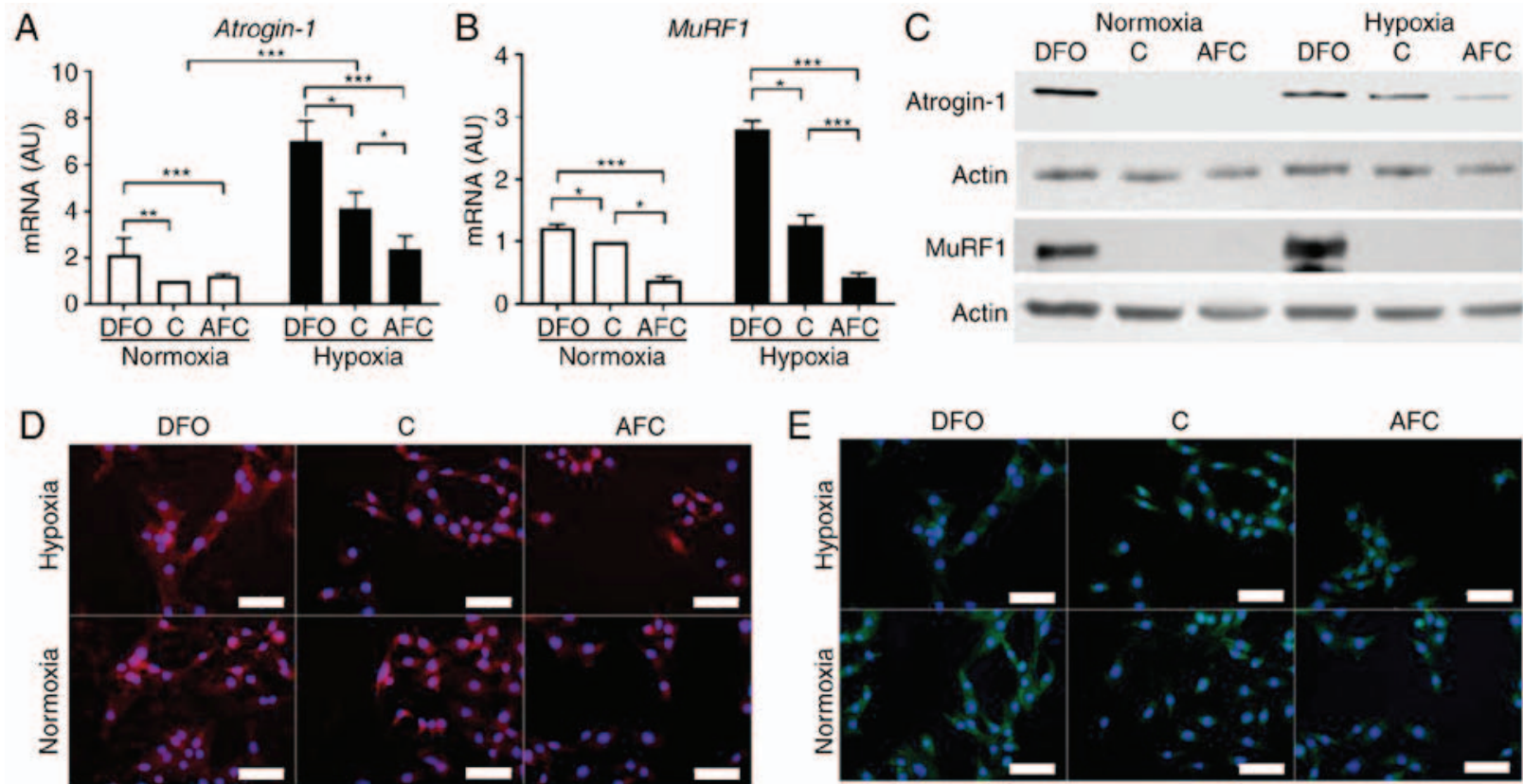

Figure 3. Expression of atrophy markers in L6G8C5 cells with concomitant optimal, reduced or increased iron availability in normoxia and hypoxia. mRNA expression levels of (A) atrogin-1 and (B) MuRF1 in L6G8C5 cells. (C) Western blot analysis of respective proteins expression in the cell lysates. Representative images of immunocytochemical staining of (D) atrogin-1 and (E) MuRF1 in L6G8C5 cell lines (with DAPI as a nuclei maker). Scalebar length, $25 \mu \mathrm{m}$. Data are presented as the mean + standard deviation obtained from three separate experiments. ${ }^{*} \mathrm{P}<0.05 ;{ }^{* *} \mathrm{P}<0.01 ;{ }^{* * * *} \mathrm{P}<0.001$. AU, arbitrary units; MuRF1, muscle-specific RING-finger 1; DFO, reduced iron concentration via deferroxamine; C, control; AFC, increased iron concentration via ammonium ferric citrate.

a shift towards atrophy in the atrophy-hypertrophy balance; whereas during normoxia, the expression of this transcription factor was not significantly changed (Fig. 4A). When exposed to iron supplementation with AFC in normoxic conditions, L6 cells exhibited a significant increase in mRNA expression of SMAD4 compared with cells cultured in optimal iron concentration $(\mathrm{P}<0.001)$. Western blot analysis and immunocytochemical staining confirmed that hypoxia treatment did not alter the protein expression of SMAD4 (Fig. 4B and C). In turn, the addition of DFO or AFC to the culture medium caused, a marked decrease or increase, respectively, in the protein level of SMAD4 during hypoxia and normoxia, compared with the cells cultured in optimal iron concentrations (Fig. 4B and C). Notably, the mRNA expression of SMAD4 during hypoxia and concomitant different iron status was significantly associated with mRNA expression of Tfr1 (24) $(\mathrm{R}=-0.94, \mathrm{P}<0.01)$ and 

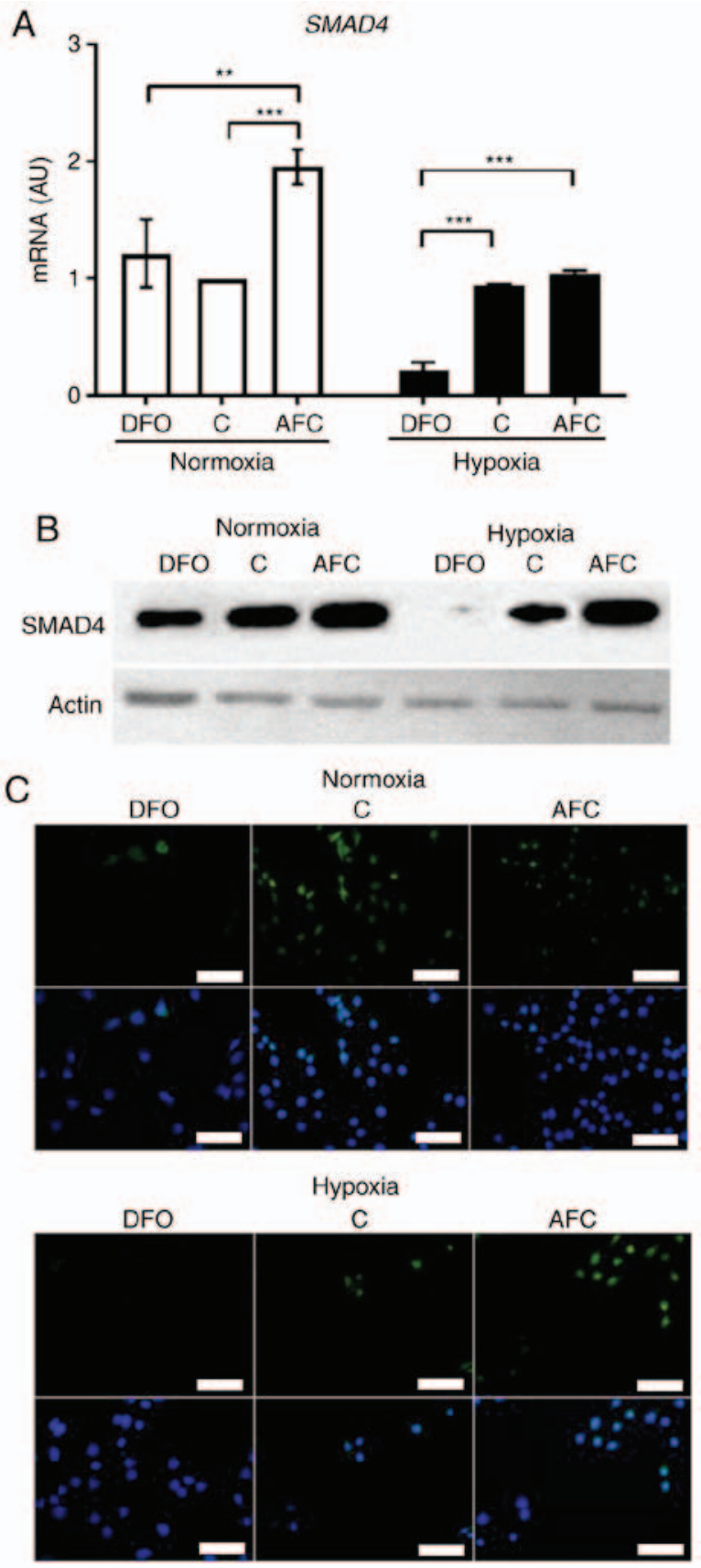

Figure 4. Expression of SMAD4 in L6G8C5 cells with concomitant optimal, reduced or increased iron availability in normoxia and hypoxia. (A) mRNA expression levels of SMAD4 in L6G8C5 cells. (B) Western blot analysis of respective proteins expression in the cell lysates. (C) Representative images of immunocytochemical staining of SMAD4 and DAPI as a nuclei marker in L6G8C5 cell lines. Scalebar length, $25 \mu \mathrm{m}$. Data are presented as the mean + standard deviation obtained from three separate experiments. ${ }^{* * *} \mathrm{P}<0.01 ;{ }^{* * *} \mathrm{P}<0.001$. AU, arbitrary units; $\mathrm{DFO}$, reduced iron concentration via deferroxamine; $\mathrm{C}$, control; $\mathrm{AFC}$, increased iron concentration via ammonium ferric citrate; SMAD4, mothers against decapentaplegic homolog 4 .

apoptotic activity measured as Bax/Bcl-2 (24) gene expression ratio $(\mathrm{R}=-0.79, \mathrm{P}<0.05)$ (data not shown). The aforementioned associations were not present upon normoxic conditions.

Effects of different iron availability on the expression of desmin in skeletal myocytes. Reduced iron availability resulted in significantly increased mRNA expression of desmin during normoxia and hypoxia, compared with the cells cultured in
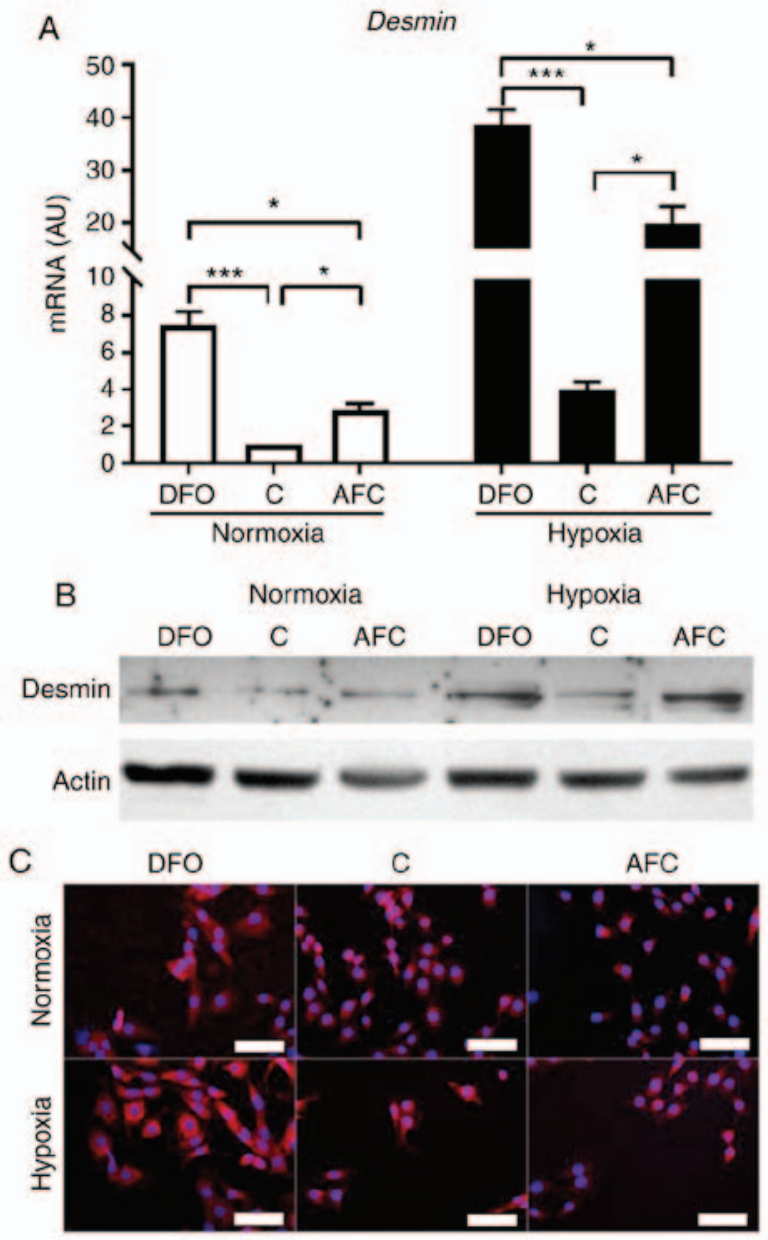

Figure 5. Expression of Desmin in L6 cells with concomitant optimal, reduced or increased iron availability in normoxia and hypoxia. (A) mRNA expression levels of Desmin in L6G8C5 cells. (B) Western blot analysis of respective proteins expression in the cell lysates. (C) Representative images of immunocytochemical staining of Desmin with DAPI as a nuclei marker in L6G8C5 cell lines. Scalebar length, $25 \mu \mathrm{m}$. ${ }^{*} \mathrm{P}<0.05 ;{ }^{* * * *} \mathrm{P}<0.001$. AU, arbitrary units; DFO, reduced iron concentration via deferroxamine; $\mathrm{C}$, control; $\mathrm{AFC}$, increased iron concentration via ammonium ferric citrate.

optimal iron concentrations (both, $\mathrm{P}<0.001$ ). Notably, the increase of desmin mRNA expression was markedly greater in low iron conditions during hypoxia than in reduced iron levels in normoxic conditions. Similarly, when exposed to AFC treatment, L6 skeletal myocytes exhibited a significant increase in the mRNA expression of desmin during normoxia and hypoxia, compared with the cells cultured in optimal iron concentrations (both, $\mathrm{P}<0.05$ ). The increase of mRNA expression of desmin was greater during hypoxia upon low iron treatment than in AFC-treated cells in normoxia. Western blot analysis (Fig. 5B) and immunocytochemical staining (Fig. 5C) revealed a similar pattern of changes at the protein level. Notably, the expression of desmin was significantly associated with increased mRNA expression of TfRl (24) during both normoxia and hypoxia, regardless of iron level $(\mathrm{R}=0.71, \mathrm{P}<0.05 ; \mathrm{R}=0.79, \mathrm{P}<0.05)$. Furthermore, the expression of desmin during hypoxia with concomitant different iron status was significantly associated with apoptotic activity measured as the $\mathrm{Bax} / \mathrm{Bcl}$-2 (24) gene expression ratio $(\mathrm{R}=0.93, \mathrm{P}<0.001)$ and with the decreased mRNA expression of SMAD4 $(\mathrm{R}=-0.80, \mathrm{P}<0.01)$ (data not shown). 


\section{Discussion}

The present study provides an insight into the response of muscle-specific atrophy markers to increased or reduced iron availability in skeletal myocytes when cultured under normoxic or hypoxic conditions. In particular, it was demonstrated that iron depletion, when combined with hypoxia, induced abnormal cell morphology and an upregulation of key enzymatic components of intracellular regulatory system of muscle atrophy, namely muscle-specific ubiquitin E3-ligases Atrogin-1 and MuRF1. Notably, it was demonstrated that augmented iron availability in hypoxic conditions acted in a protective manner in the context of these atrophy markers.

Skeletal muscle wasting has been insufficiently investigated in the context of iron metabolism. To date, there have been few studies that linked iron overload to muscle atrophy. For example, Ikeda et al (40) recently demonstrated that excess iron caused a decrease in mean size and muscle fibre area as well as an induction of Atrogin-1 and MuRF1 expression in mice subjected to 7- or 14-day iron injection treatment. However, it should be emphasized that animals that underwent the aforementioned experiment were healthy and, apart from iron load, no other factors mimicking any pathology were investigated in this study. Similarly, Reardon and Allen (41) previously demonstrated an iron-induced atrophy observed in murine skeletal muscle, but the process occurred only in soleus muscles and was not detected within the rest of the investigated muscles. There is also a scarcity of data on the influence of both iron excess and iron deficiency on atrophy markers in skeletal myocytes when exposed to hypoxia. The present authors previously studied the influence of increased or reduced iron availability in hypoxic conditions on skeletal myocytes and demonstrated that, during hypoxia, the reduced iron concentration had a more negative impact on the viability and apoptotic activity of the studied cells as compared with elevated iron availability $(24,42)$. The present authors' preliminary results also demonstrated that, in skeletal myocytes, the mRNA expression of muscle-specific atrophy marker Atrogin- 1 was increased upon reduced iron availability, and was downregulated in increased iron concentrations (24).

In the present study, it was demonstrated that skeletal myocytes exposed to an iron-deficient environment demonstrated an upregulation of Atrogin- 1 and $M u R F 1$ at the mRNA and protein levels in hypoxia and normoxia, which suggested that catabolic activation and resulting protein degradation had occurred in the cells. The most severe impact in the context of muscle atrophy markers was observed in the combined conditions of hypoxia and iron deficiency. Notably, AFC-treated cells demonstrated an opposing trend, which suggested a protective influence of iron supplementation. This may support a molecular substantiation of efficacy of iron therapy for the improvement of muscle functional capacity in iron-deficient patients with $\operatorname{HF}(22,23)$. Notably, the observed upregulation of both Atrogin-1 and MuRF1 in low-iron availability introduced in hypoxia was associated with increased expression of Tfrl, reflecting the association between an increased intracellular iron demand and catabolic activation of skeletal myocytes.

As the morphology of cells cultured in and iron-deficient environment was altered both in normoxia and hypoxia as compared with optimal or augmented iron availability, the expression of desmin, a muscle-specific cytoskeletal intermediate filament, was investigated $(43,44)$. To the best of our knowledge, desmin has not previously been analysed in skeletal muscle in the context of iron availability. In the present study, it was demonstrated that reduced and increased iron concentration lead to the upregulation of desmin, whereas hypoxia strengthened this effect. The aforementioned alterations may be considered as a maladaptive mechanism resulting in abnormal desmin accumulation, which has recently been correlated with altered myofiber morphology or mitochondrial dysfunction (45). In another previous study, an increased expression of desmin in aging rat muscles was potentially linked to the altered contractile force (46). In the present study, it was demonstrated that both iron overload and iron depletion were associated with desmin accumulation, which was analogous to the association previously reported by Walter et al (47) who demonstrated the detrimental effect of both iron overload and iron deficiency on the function of liver mitochondria. However, it is notable that the greatest augmentation of desmin expression was observed in DFO-treated cells cultured in hypoxia, which suggests that these combined conditions have the most negative impact on the cell structure.

The influence of differing iron availability on skeletal myocytes cultured in hypoxic conditions has been poorly investigated also in the context of atrophy-hypertrophy balance thus far, therefore the expression of SMAD4 was investigated, which is associated with equilibrium between novel protein accumulation and the degradation of existing proteins $(28,29)$. Notably, Sartori et al (30) previously revealed the occurrence of atrophy changes in the skeletal muscle of SMAD4-deficient mice. In the present study, it was discovered that, under hypoxia, reduced iron availability induced a decrease in SMAD4 expression. This finding indicated that environmental iron limitation along with reduced oxygen may contribute to muscle atrophy. It was also demonstrated that, in hypoxic conditions, the increased iron concentration may be protective as it induced an increase in SMAD4 expression, and therefore, a potential shift towards hypertrophy.

Together, the present data suggested that the combined conditions of hypoxia and iron deficiency are the most detrimental for skeletal myocytes in the context of morphology alterations and expression of atrophy markers. Conversely, it appears that elevated iron availability in hypoxic conditions may be beneficial to a certain extent for skeletal myocytes, preventing their catabolic activation. Although it is necessary to verify these results in more advanced experimental models, they still may provide a valuable starting point for the understanding of efficacy of iron therapy for the improvement of muscle functional capacity and exercise tolerance observed in patients with $\mathrm{HF}$ and concomitant iron deficiency.

Furthermore, it may be interesting to further investigate the level of atrophy markers in human skeletal muscle tissue samples obtained from iron-deficient patients with HF prior to and following receiving intravenous iron supplementation.

\section{Funding}

The present study was financially supported by the National Science Centre (Kraków, Poland; grant no. DEC-2012/ 05/E/NZ5/00590). 


\section{Competing interests}

Wrocław Medical University received an unrestricted grant from Vifor Pharma outside the submitted work. Monika Kasztura reports financial support from Vifor Pharma for travel and accommodation for scientific meeting. Waldemar Banasiak reports personal fees from Vifor Pharma, outside the submitted work. Piotr Ponikowski reports personal fees from Vifor Pharma and personal fees from AMGEN, outside the submitted work. Ewa A. Jankowska reports personal fees from Vifor Pharma and FRESENIUS, outside the submitted work.

\section{References}

1. Cohen S, Nathan JA and Goldberg AL: Muscle wasting in disease: Molecular mechanisms and promising therapies. Nat Rev Drug Discov 14: 58-74, 2015.

2. Jackman RW and Kandarian SC: The molecular basis of skeletal muscle atrophy. Am J Physiol Cell Physiol 287: C834-C843, 2004.

3. Sillau AH and Banchero N: Effects of hypoxia on capillary density and fiber composition in rat skeletal muscle. Pflugers Arch 370: 227-232, 1977

4. Zattara-Hartmann MC, Badier M, Guillot C, Tomei C and Jammes Y: Maximal force and endurance to fatigue of respiratory and skeletal muscles in chronic hypoxemic patients: The effects of oxygen breathing. Muscle Nerve 18: 495-502, 1995.

5. Sanders KJ, Kneppers AE, van de Bool C, Langen RC and Schols AM: Cachexia in chronic obstructive pulmonary disease: New insights and therapeutic perspective. J Cachexia Sarcopenia Muscle 7: 5-22, 2016.

6. Clark AL, Poole-Wilson PA and Coats AJ: Exercise limitation in chronic heart failure: Central role of the periphery. J Am Coll Cardiol 28: 1092-1102, 1996.

7. Coats A: The 'Muscle Hypothesis' of chronic heart failure. J Mol Cell Cardiol 28: 2255-2262, 1996.

8. Coats AJ, Clark AL, Piepoli M, Volterrani M and Poole-Wilson PA: Symptoms and quality of life in heart failure: The muscle hypothesis. Br Heart J 72 (Suppl 2): S36-S39, 1994.

9. Piepoli MF, Kaczmarek A, Francis DP, Davies LC, Rauchhaus M, Jankowska EA, Anker SD, Capucci A, Banasiak W and Ponikowski P: Reduced peripheral skeletal muscle mass and abnormal reflex physiology in chronic heart failure. Circulation 114: 126-134, 2006.

10. Mancini DM, Walter G, Reichek N, Lenkinski R, McCully KK, Mullen JL and Wilson JR: Contribution of skeletal muscle atrophy to exercise intolerance and altered muscle metabolism in heart failure. Circulation 85: 1364-1373, 1992.

11. Farkas J, von Haehling S, Kalantar-Zadeh K, Morley JE, Anker SD and Lainscak M: Cachexia as a major public health problem: Frequent, costly, and deadly. J Cachexia Sarcopenia Muscle 4: 173-178,2013.

12. Hajahmadi M, Shemshadi S, Khalilipur E, Amin A, Taghavi S, Maleki M, Malek H and Naderi N: Muscle wasting in young patients with dilated cardiomyopathy. J Cachexia Sarcopenia Muscle 8: 542-548, 2017.

13. Buller NP, Jones D and Poole-Wilson PA: Direct measurement of skeletal muscle fatigue in patients with chronic heart failure. $\mathrm{Br}$ Heart J 65: 20-24, 1991

14. Stugiewicz M, Tkaczyszyn M, Kasztura M, Banasiak W, Ponikowski P and Jankowska EA: The influence of iron deficiency on the functioning of skeletal muscles: Experimental evidence and clinical implications. Eur J Heart Fail 18: 762-773, 2016.

15. Loncar G, Springer J, Anker M, Doehner W and Lainscak M: Cardiac cachexia: Hic et nunc. J Cachexia Sarcopenia Muscle 7: 246-260, 2016

16. Zizola C and Schulze PC: Metabolic and structural impairment of skeletal muscle in heart failure. Heart Fail Rev 18: 623-630, 2013

17. Gosker HR, Wouters EF, van der Vusse GJ and Schols AM: Skeletal muscle dysfunction in chronic obstructive pulmonary disease and chronic heart failure: Underlying mechanisms and therapy perspectives. Am J Clin Nutr 71: 1033-1047, 2000.

18. von Haehling S, Lainscak M, Springer J and Anker SD: Cardiac cachexia: A systematic overview. Pharmacol Ther 121: 227-252, 2009.
19. Minotti JR, Christoph I, Oka R, Weiner MW, Wells L and Massie BM: Impaired skeletal muscle function in patients with congestive heart failure. Relationship to systemic exercise performance. J Clin Invest 88: 2077-2082, 1991.

20. Jankowska EA, Rozentryt $P$, Witkowska A, Nowak J, Hartmann O, Ponikowska B, Borodulin-Nadzieja L, Banasiak W, Polonski L, Filippatos G, et al: Iron deficiency: An ominous sign in patients with systolic chronic heart failure. Eur Heart J 31: 1872-1880, 2010.

21. Jankowska EA, Malyszko J, Ardehali H, Koc-Zorawska E, Banasiak W, von Haehling S, Macdougall IC, Weiss G, McMurray JJ, Anker SD, et al: Iron status in patients with chronic heart failure. Eur Heart J 34: 827-834, 2013.

22. Anker SD, Comin Colet J, Filippatos G, Willenheimer R, Dickstein K, Drexler H, Lüscher TF, Bart B, Banasiak W, Niegowska J, et al: Ferric carboxymaltose in patients with heart failure and iron deficiency. N Engl J Med 361: 2436-2448, 2009.

23. Okonko DO, Grzeslo A, Witkowski T, Mandal AKJ, Slater RM, Roughton M, Foldes G, Thum T, Majda J, Banasiak W, et al: Effect of intravenous iron sucrose on exercise tolerance in anemic and nonanemic patients with symptomatic chronic heart failure and iron deficiency. J Am Coll Cardiol 51: 103-112.

24. Dziegala M, Kasztura M, Kobak K, Bania J, Banasiak W, Ponikowski P and Jankowska EA: Influence of the availability of iron during hypoxia on the genes associated with apoptotic activity and local iron metabolism in rat $\mathrm{H} 9 \mathrm{C} 2$ cardiomyocytes and L6G8C5 skeletal myocytes. Mol Med Rep 14: 3969-3977, 2016.

25. Gomes MD, Lecker SH, Jagoe RT, Navon A and Goldberg AL: Atrogin-1, a muscle-specific F-box protein highly expressed during muscle atrophy. Proc Natl Acad Sci 98: 14440-14445, 2001.

26. Bodine SC, Latres E, Baumhueter S, Lai VK, Nunez L, Clarke BA, Poueymirou WT, Panaro FJ, Na E, Dharmarajan K, et al: Identification of ubiquitin ligases required for skeletal muscle atrophy. Science 294: 1704-1708, 2001.

27. Palus S, von Haehling S and Springer J: Muscle wasting: An overview of recent developments in basic research. J Cachexia Sarcopenia Muscle 5: 193-198, 2014

28. Liu F, Pouponnot C and Massagué J: Dual role of the Smad4/DPC4 tumor suppressor in TGFbeta-inducible transcriptional complexes. Genes Dev 11: 3157-3167, 1997.

29. Seong HA, Jung H, Kim KT and Ha H: 3-Phosphoinositidedependent PDK1 negatively regulates transforming growth factor- $\beta$-induced signaling in a kinase-dependent manner through physical interaction with Smad Proteins. J Biol Chem 282: 12272-12289, 2007.

30. Sartori R, Schirwis E, Blaauw B, Bortolanza S, Zhao J, Enzo E, Stantzou A, Mouisel E, Toniolo L, Ferry A, et al: BMP signaling controls muscle mass. Nat Genet 45: 1309-1318, 2013.

31. Aliparasti MR, Alipour MR, Almasi S and Feizi H: Ghrelin administration increases the $\mathrm{Bax} / \mathrm{Bcl}-2$ gene expression ratio in the heart of chronic hypoxic rats. Adv Pharm Bull 5: 195-199, 2015.

32. Fletcher J: Iron transport in the blood. Proc R Soc Med 63: 1216-1218, 1970.

33. Woo KJ, Lee TJ, Park JW and Kwon TK: Desferrioxamine, an iron chelator, enhances HIF-1alpha accumulation via cyclooxygenase-2 signaling pathway. Biochem Biophys Res Commun 343: $8-14,2006$.

34. Parkes JG, Hussain RA, Olivieri NF and Templeton DM: Effects of iron loading on uptake, speciation, and chelation of iron in cultured myocardial cells. J Lab Clin Med 122: 36-47, 1993.

35. Hoepken HH, Korten T, Robinson SR and Dringen R: Iron accumulation, iron-mediated toxicity and altered levels of ferritin and transferrin receptor in cultured astrocytes during incubation with ferric ammonium citrate. J Neurochem 88: 1194-1202, 2004.

36. Chandio ZA, Talpur FN, Khan H, Afridi HI and Khaskheli GQ: Determination of cadmium and zinc in vegetables with online FAAS after simultaneous pre-concentration with 1,5-diphenylthiocarbazone immobilised on naphthalene. Food Addit Contam Part A Chem Anal Control Expo Risk Assess 30: 110-115, 2013.

37. Lowry OH, Rosebrough NJ, Farr AL and Randall RJ: Protein measurement with the folin phenol reagent. J Biol Chem 193: 265-275, 1951.

38. Pfaffl MW: A new mathematical model for relative quantification in real-time RT-PCR. Nucleic Acids Res 29: e45, 2001.

39. Walker JM: The bicinchoninic acid (BCA) assay for protein quantitation. Methods Mol Biol 32: 5-8, 1994. 
40. Ikeda Y,Imao M, Satoh A, Watanabe H,Hamano H, Horinouchi Y, Izawa-Ishizawa Y, Kihira Y, Miyamoto L, Ishizawa K, et al: Iron-induced skeletal muscle atrophy involves an Akt-forkhead box O3-E3 ubiquitin ligase-dependent pathway. J Trace Elem Med Biol 35: 66-76, 2016.

41. Reardon TF and Allen DG: Iron injections in mice increase skeletal muscle iron content, induce oxidative stress and reduce exercise performance. Exp Physiol 94: 720-730, 2009.

42. Kasztura M, Dzięgała M, Kobak K, Bania J, Mazur G, Banasiak W, Ponikowski P and Jankowska EA: Both iron excess and iron depletion impair viability of rat $\mathrm{H} 9 \mathrm{C} 2$ cardiomyocytes and L6G8C5 myocytes. Kardiol Pol 75: 267-275, 2017.

43. Sequeira V, Nijenkamp LL, Regan JA and van der Velden J: The physiological role of cardiac cytoskeleton and its alterations in heart failure. Biochim Biophys Acta 1838: 700-722, 2014.

44. Lazarides E and Hubbard BD: Immunological characterization of the subunit of the 100 A filaments from muscle cells. Proc Natl Acad Sci USA 73: 4344-4348, 1976.
45. Koutakis P, Miserlis D, Myers SA, Kim JK, Zhu Z, Papoutsi E, Swanson SA, Haynatzki G, Ha DM, Carpenter LA, et al: Abnormal accumulation of desmin in gastrocnemius myofibers of patients with peripheral artery disease. J Histochem Cytochem 63: 256-269, 2015.

46. Russ DW and Grandy JS: Increased desmin expression in hindlimb muscles of aging rats. J Cachexia Sarcopenia Muscle 2: 175-180, 2011.

47. Walter PB, Knutson MD, Paler-Martinez A, Lee S, Xu Y, Viteri FE and Ames BN: Iron deficiency and iron excess damage mitochondria and mitochondrial DNA in rats. Proc Natl Acad Sci USA 99: 2264-2269, 2002.

This work is licensed under a Creative Commons Attribution-NonCommercial-NoDerivatives 4.0 International (CC BY-NC-ND 4.0) License. 